\title{
Patient concern inventory: an effective tool for easing telemedicine during the COVID-19 pandemic
}

\author{
Satvinder Singh Bakshi (D) Vinoth Kumar Kalidoss
}

Received: 16 March 2021 / Accepted: 22 March 2021 / Published online: 14 April 2021

(c) Springer-Verlag GmbH Austria, part of Springer Nature 2021

\section{Dear Editors,}

The coronavirus disease 2019 (COVID-19) pandemic has overwhelmed the existing healthcare systems globally. Telemedicine is a convenient and inexpensive strategy for providing health care during disasters and public health emergencies [1]. Teleconsultation technologies provide care not only to an individual but also to a broad population base. Although telemedicine has been practiced for many years concept, setting up an effective telemedicine system rapidly is still a challenge [2].

A major drawback of teleconsultation is that patients may not express their concerns due to the lack of time, which in turn can result in some health problems being unrecognized and lead to patient dissatisfaction. Addition of text-based information improves the efficiency of teleconsultation and makes it more satisfactory [3]. One of the problems faced in using such text communication is that patients do not know which and how much information needs to be entered, which in turn can reduce their satisfaction.

Patient concern inventory (PCI) is a structured patient reporting tool that aids in identifying concerns and issues. The PCI may contain several domains like physical complaints, previous treatment and status of functional, psychological and social well-being. PCI can manage the logic flow of patients and referral services according to severity and need [4]. Accordingly,

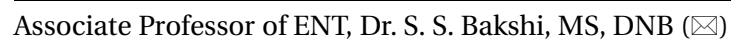

Department of ENT and Head \& Neck Surgery, AIIMS

Mangalagiri, 522503 Guntur, Andhra Pradesh, India

saty.bakshi@gmail.com

Dr. V. K. Kalidoss, MD MPH

Department of Community and Family Medicine, AIIMS

Mangalagiri, 522503 Guntur, Andhra Pradesh, India vinob4u@gmail.com patients can be triaged and they can schedule audio video visits appropriately, which will avoid unnecessary waiting time and increase the efficiency of the teleconsultation. One example of successful development of a PCI model is the one used for head and neck cancer (PCIHNC) [5]. It was shown to be effective in identifying concerns and issues of the patients and helped provide holistic care to the patients.

Studies have shown that the use of this tool has multiple advantages [5]. These include standardizing the teleconsultation, aid multiprofessional communication, increased discussion on patient concerns, avoiding missing key issues and reduction in the patient waiting time. It will also help in effective utilization of healthcare force by delegating teleconsultation for minor illness to experienced members which in turn will free up the senior experienced staff. Another advantage is that it can be rapidly deployed and does not require any additional IT for its use [4]. In addition, hospitals with specific hospital management information system can easily incorporate the PCI into their existing system. During the COVID 19 pandemic, telemedicine with suitable patient care inventory is suitable across many different healthcare settings in both developing and developed countries.

Conflict of interest S.S. Bakshi and V.K. Kalidoss declare that they have no competing interests.

\section{References}

1. Webster P.Virtualhealth carein the era ofCOVID-19. Lancet. 2020;395(10231):1180-1.

2. Keesara S, Jonas A, Schulman K. Covid-19 and health care's digital revolution. N Engl J Med. 2020;382(23):e82-4. https:// doi.org/10.1056/NEJMp2005835.

3. Medical Council of India. Telemedicine practice guidelines enabling registered medical practitioners to provide 
healthcare using telemedicine. 2020. https://www.mohfw. gov.in/pdf/Telemedicine.pdf. Accessed 27 Apr 2020.

4. Kanatas A, Rogers SN. Therole of the Head and Neck cancerspecific Patient Concerns Inventory (PCI-HN) in telephone consultations during the COVID-19 pandemic. Br J Oral Maxillofac Surg. 2020;58(5):497-9. https://doi.org/10. 1016/j.bjoms.2020.04.010.
5. Ghazali N, Kanatas A, Bekiroglu F, Scott B, Lowe D, Rogers S. The patient concerns inventory: a tool to uncover unmet needs in a cancer outpatient clinic. Bull R Coll Surg Engl. 2013;95(3):1-6.

Publisher's Note Springer Nature remains neutral with regard to jurisdictional claims in published maps and institutional affiliations. 